OPEN ACCESS

Edited by: Cristian Apetrei, University of Pittsburgh, United States

Reviewed by: Shaohui Wang, Cedars Sinai Medical Center, United States Sita Awasthi, University of Pennsylvania,

United States

${ }^{*}$ Correspondence: Konstantin G. Kousoulas vtgusk@/su.edu

Specialty section: This article was submitted to Viral Immunology, a section of the journal

Frontiers in Immunology

Received: 04 October 2021 Accepted: 25 October 2021 Published: 15 November 2021

Citation:

Nabi R, Lewin AC, Collantes TM,

Chouljenko VN and Kousoulas KG (2021) Intramuscular Vaccination With the HSV-1NC2) Live-Attenuated Vaccine

Strain Confers Protection Against Viral Ocular Immunopathogenesis Associated With $\gamma \delta T$ Cell Intracorneal Infiltration

Front. Immunol. 12:789454. doi: 10.3389/fimmu.2021.789454

\section{Intramuscular Vaccination With the HSV-1(VC2) Live-Attenuated Vaccine Strain Confers Protection Against Viral Ocular Immunopathogenesis Associated With $\gamma \delta T$ Cell Intracorneal Infiltration}

\author{
Rafiq Nabi ${ }^{1}$, Andrew C. Lewin ${ }^{2}$, Therese M. Collantes ${ }^{1}$, Vladimir N. Chouljenko ${ }^{1}$ \\ and Konstantin G. Kousoulas ${ }^{1 *}$ \\ ${ }^{1}$ Department of Pathobiological Science, Louisiana State University School of Veterinary Medicine, Baton Rouge, LA, United \\ States, ${ }^{2}$ Department of Veterinary Clinical Sciences, Louisiana State University School of Veterinary Medicine, Baton Rouge, \\ $L A$, United States
}

Herpes simplex virus type-1 (HSV-1) ocular infection is one of the leading causes of infectious blindness in developed countries. The resultant herpetic keratitis $(\mathrm{HK})$ is caused by an exacerbated reaction of the adaptive immune response that persists beyond virus clearance causing substantial damage to the cornea. Intramuscular immunization of mice with the HSV-1(VC2) live-attenuated vaccine strain has been shown to protect mice against lethal ocular challenge. Herein, we show that following ocular challenge, VC2 vaccinated animals control ocular immunopathogenesis in the absence of neutralizing antibodies on ocular surfaces. Ocular protection is associated with enhanced intracorneal infiltration of $\gamma \delta$ T cells compared to mock-vaccinated animals. The observed $\gamma \delta$ T cellular infiltration was inversely proportional to the infiltration of neutrophils, the latter associated with exacerbated tissue damage. Inhibition of T cell migration into ocular tissues by the S1P receptors agonist FTY720 produced significant ocular disease in vaccinated mice and marked increase in neutrophil infiltration. These results indicate that ocular challenge of mice immunized with the VC2 vaccine induce a unique ocular mucosal response that leads into the infiltration of $\gamma \delta \mathrm{T}$ cells resulting in the amelioration of infectionassociated immunopathogenesis.

Keywords: herpes simplex, gamma delta T cells, immunopathogenesis, ocular infection, herpes keratitis

\section{INTRODUCTION}

Herpetic Keratitis (HK) induced by herpes simplex virus type 1 (HSV-1) ocular infection is a leading cause of infectious blindness. It is estimated that $50-90 \%$ of the world population is infected with HSV-1 (1-3). Primary infection of HSV-1 targets mucosal regions such as the oral lining and skin (4). After the establishment of latency in the trigeminal ganglion (TG), HSV-1 can reactivate due to 
various environmental factors and physiological stress, leading to HK $(5,6)$. HK is widely considered to be an immune-mediated condition where uncontrolled inflammatory events continue to damage the cornea during and after the resolution of infection (7).

The use of animal models such as mice and rabbits is wellestablished in ocular HSV-1 research (6). Data from these animal models suggest that after initial reactivation from the TG, the virus travels to the ocular surface in an anterograde manner (8, 9). The presence of the virus on the ocular surface activates several innate immune pathways (10) that lead to inflammation and subsequent tissue damage. It has been suggested that vaccine-induced immunity can reduce HSV-1 induced HK in animal models (11-17). However, there is currently no approved vaccine for clinical use. Previously, we reported that intramuscular immunization (IM) with the live-attenuated HSV-1 vaccine (VC2) confers complete protection against a lethal HSV-1 challenge and ocular immunopathogenesis (18-20).

The HSV-1 (VC2) vaccine strain derived from the laboratory attenuated parental HSV-1 (F) strain specifies glycoprotein K (gK) having a 39 amino-terminal deletion of glycoprotein $\mathrm{K}$ (gK). This amino acid deletion has been shown to prevent entry into cells via fusion of the viral membrane with cellular plasma membranes including neuronal axons. In contrast, the virus replicates efficiently in a variety of cells, because it can enter through endocytosis (21-23). In addition, the VC2 vaccine strain has a deletion in the amino terminus of the membrane protein UL20 that interacts with the carboxyl terminus of glycoprotein B (gB). The UL20 protein functions as a heterodimer with $\mathrm{gK}$ to modulate the fusogenic properties of $\mathrm{gB}$ and both $\mathrm{gK}$. Thus, the combined effect of the gK/UL20 mutations provide a unique safety feature to the VC2 virus, since it cannot infect neurons via neuronal axons and establish latency (24-30). HSV-1 gK has an important role in virus-induced corneal scaring (CS). Specifically, immunization with $\mathrm{gK}$ or overexpression of $\mathrm{gK}$ caused exacerbated virus-induced CS. gK-induced CS depends on $\mathrm{gK}$ binding to signal peptidase (SPP), while its binding partner UL20 binds GODZ (DHHC3) that are involved in $\mathrm{gK}-$ induced pathology (31-35).

HSV-1 infection of the corneal epithelium induces a cascade of antiviral innate and downstream adaptive immune responses (10). Innate responses are mediated by neutrophils, plasmacytoid dendritic cells (pDCs), natural killer (NK) cells and macrophages (MQ), which have direct and indirect antiviral functions (36-39). These innate responses possess potent antiviral activity, however, exacerbated responses can cause tissue damage. This phenomenon is particularly true for tissue damage caused by neutrophil accumulation in two separate waves $(39,40)$ despite their beneficial role in viral clearance $(39,41)$. Innate immune responses are followed by the adaptive immune response, which mainly involves CD4+T and CD8+T cells appearing as early as 3 days post-infection exhibiting potent antiviral activities that limit viral spread $(42,43)$. However, an exacerbated adaptive CD4+T cell response and to a lesser extent a CD8+T cell response can lead to corneal epithelium damage and herpetic stromal disease (44). Thus, a balanced immune response at ocular surfaces is needed to control excessive inflammation and tissue damage, particularly in the case of herpes ocular infections.

Herein, we report that intramuscular immunization of mice with the VC2 vaccine strain, but not with UV-inactivated VC2 or mock-vaccination, induced ocular protection against lethal ocular challenge with the human ocular and highly pathogenic clinical strain HSV-1(McKrae). This tissue-specific protection was associated with $\gamma \delta \mathrm{T}$ cell infiltration with reduced neutrophil accumulation compared to groups received mock and inactivated vaccine. Further, observations suggest that this infiltrated population is not HSV-1 specific memory population although their presence is required to control immunopathogenesis induced by the infection.

\section{MATERIALS AND METHODS}

\section{Cells and Viruses}

African green monkey (Vero) cells were maintained in complete Dulbecco's Modified Eagle Medium (DMEM) (Gibco) supplemented with 10\% Fetal Calf Serum (FBS) (ThermoFisher). VC2 was constructed as described previously (30). Briefly, the VC2 recombinant virus was constructed utilizing the two-step Double-Red Recombination protocol using the HSV-1(F) viral genome cloned as a bacterial artificial chromosome (BAC). The virus was cultivated in Vero cells. HSV-1((McKrae) was a gift by the late Dr. James Hill (Louisiana State University Health Sciences, Center, New Orleans, LA).

\section{Vaccination Schedule and Challenge}

Female Balb/CJ mice (8-10-week-old) were purchased from Jackson Laboratories, (Bar Harbor, ME USA) and were housed in the Louisiana State University School of Veterinary Medicine (LSU-SVM) ABSL2 facility. A prime-boost vaccination strategy was used. For prime, $100 \mu$ l of vaccine $\left(10^{7} \mathrm{PFU}\right.$ in DMEM) were injected intramuscularly into the right hind leg followed by a booster dose into the left hind leg 21 days later. Mock vaccinated animals received PBS. All animals were challenged 21 days or 8 months after the last vaccination with a lethal dose (10\% /eye) of HSV-1 (McKrae). For challenge, animals were anesthetized, and a linear partial epithelial corneal debridement was performed with a $27 \mathrm{G}$ needle before $10 \mu \mathrm{l}$ of HSV-1 (McKrae) was applied to the ocular surface. Animals were observed daily for clinical signs of disease and euthanized as described in the IACUC euthanasia criteria.

\section{Ocular Scoring}

Ocular scoring of mice was performed by Dr. Andrew Lewing, a board-certified veterinary ophthalmologist (ACL) according to a modified established ocular disease scoring system (45). Briefly, this scoring system provides objective categorization of corneal opacity, corneal neovascularization, corneal ulceration and ocular discharge [see Table $\mathbf{1}$ for the scoring system]. All examinations were performed following induction of a light 
TABLE 1 | Ocular scoring system of mice.

\begin{tabular}{|c|c|c|}
\hline Category & Score & Description \\
\hline \multirow[t]{3}{*}{ Ocular Discharge } & 0 & Normal \\
\hline & 1 & $\begin{array}{l}\text { Mild ocular discharge - usually watery/clear, } \\
\text { covering skin and fur surrounding eye }\end{array}$ \\
\hline & 2 & $\begin{array}{l}\text { Severe ocular discharge - usually yellow/tenacious, } \\
\text { covering skin and fur surrounding eye. Palpebral } \\
\text { fissure may be initially sealed due to copious } \\
\text { discharge. }\end{array}$ \\
\hline \multirow{3}{*}{$\begin{array}{l}\text { Corneal Opacity } \\
\text { (scar/edema) }\end{array}$} & 0 & Normal \\
\hline & 1 & $\begin{array}{l}\text { Mild corneal opacity due to edema and/or corneal } \\
\text { fibrosis. Can typically make out intraocular detail } \\
\text { using slit beam }\end{array}$ \\
\hline & 2 & $\begin{array}{l}\text { Severe corneal opacity due to edema and/or } \\
\text { corneal fibrosis. Cannot typically visualize intraocular } \\
\text { detail using slit beam }\end{array}$ \\
\hline \multirow{3}{*}{$\begin{array}{l}\text { Corneal } \\
\text { Neovascularization }\end{array}$} & 0 & Normal \\
\hline & 1 & $\begin{array}{l}\text { Mild corneal neovascularization. Small number (1-2) } \\
\text { of thin blood vessels, extending into cornea from } \\
\text { limbus }\end{array}$ \\
\hline & 2 & $\begin{array}{l}\text { Severe corneal neovascularization. Large number } \\
(3+) \text { or blood vessels of varying diameter, extending } \\
\text { into cornea from limbus }\end{array}$ \\
\hline \multirow[t]{3}{*}{ Corneal Ulceration } & 0 & Normal \\
\hline & 1 & $\begin{array}{l}\text { Visible corneal ulceration using slit lamp, extending } \\
\text { into corneal stroma }\end{array}$ \\
\hline & 2 & Visible corneal perforation using slit lamp \\
\hline
\end{tabular}

Adapted from Eaton et al., 2017 (45).

plane of anesthesia using inhaled isoflurane in oxygen using a handheld biomicroscope (Kowa, SL-17). Normal animals were assigned a score of 0 per eye, and animals with ocular disease were assigned a score of up to 8 per eye, for a maximum possible score of 16 per animal at each time point. All animals were confirmed to be normal with a score of 0 for each eye prior to challenge and were scored again 5 days post infection.

\section{Tissue Processing and Flow Cytometry}

The whole mouse eye was collected in PBS following euthanasia, mince and incubated with collagenase in HBSS buffer for 2 hours. The homogenized solution was passed through a $70 \mu \mathrm{m}$ filter to prepare a single cell solution. Mandibular lymph nodes $(\mathrm{mLN})$ were collected and processed through a $70 \mu \mathrm{m}$ filter to prepare a single cell solution. A pre-titrated antibody mixture was incubated for 30 minutes at $4^{\circ} \mathrm{C}$, washed and fixed with $2 \%$ paraformaldehyde. The next day, samples were analyzed using the BD FACS-Aria equipment and data was processed using FCS Express 7. The anti-mouse antibodies used for flow cytometry were; CD45-APC Vio770, Ly6G-PE CF594, CD3-PerCP-ef710, CD4-FITC, CD8a-BV650, $\gamma \delta$ TCR-APC, MHCii-BV711, CD11C-PE. CD64-BV605, CD49b-BV421, CD19-BV786, CD44-BV711 and CD62L-BV421. Gating strategy is presented in Supplementary Figure S1.

\section{Immunofluorescence Microscopy and Detection of HSV-RNA Using RNAScope}

Following euthanasia, eyes were immediately fixed using $10 \%$ formalin for 3 days and processed in the Histology Core Facility of LSU-SVM. For IFM and RNAScope, $5 \mu \mathrm{m}$ thick FormalinFixed Paraffin-Embedded (FFPE) sections were prepared on glass slides. To detect viral replication, the HSV-1 UL-48 RNA was used as the target gene with the Probe-V-HSV-1-UL48-C3 purchased from Advanced Cell Diagnostics. The RNAScope assay was performed according to ACDBio guidelines using the Opal 620 dye (Akoya Biosciences) as the substrate. Following the RNAScope assay, the slides were blocked with $10 \% \mathrm{FBS}$ and incubated overnight with rabbit polyclonal antiHSV-1 (Dako). The following day slides were washed and antirabbit FITC was used as the secondary antibody. Next, the background was reduced with the TrueView auto fluorescence kit (Vectorlabs). After adding mounting media with DAPI, slides were visualized with a Zeiss observer Z1 inverse microscope.

\section{IFM on Frozen Sections}

Whole mouse eyes were collected after euthanasia and immediately frozen using OCT in liquid nitrogen. Samples were stored at $-80^{\circ} \mathrm{C}$ until processing. For microscopy, $8 \mu \mathrm{m}$ thick frozen sections were prepared on glass slides using a cryostat. Tissue sections were fixed briefly for 1 minute using $2 \%$ paraformaldehyde at room temperature (RT). After blocking with 5\% FBS for 1 hour, slides were incubated with fluorophoreconjugated primary antibody overnight at $40^{\circ} \mathrm{C}$. Slides were then washed, fixed and mounting media was added. Images were captured with a Zeiss observer Z1 microscope. The antibodies used for IFM were: Anti- $\gamma \delta T C R-A F 488$ (GL3), anti-LY6GAF594 (1A8) and Alexa Fluor 594 anti-mouse CD31 (MEEC13.3) (Biolegend. Inc.) and LYVE-1 AlexaFluor488 (ALY7) (Thermofisher, Inc).

\section{Bromodeoxyuridine Proliferation Assay}

BrdU labeling reagent (Invitrogen, cat\# 000103) was injected $(1 \mathrm{ml} / \mathrm{Kg})$ intraperitoneally (IP) on the day before challenge and administered every day following infection for 4 days. At day 5, animals were euthanized, cells were stained and fixed as mentioned above. Cells were then permeabilized using permeabilization buffer (eBioscience) and incorporated BrdU was stained using $\mathrm{Rb}$-anti-BrdU primary antibodies and $\mathrm{aRb}$ AlexaFluor488 secondary antibodies. Data was captured using a BD FACS Aria Flow cytometer and calculated as a percentage of cells positive for BrdU within a specific population.

\section{Quantification of Viral Shedding}

At 5 days post infection (dpi), viral shedding on the ocular surface was determined using plaque assay. For virus collection, a sterile cotton swab soaked in DMEM was swabbed gently on the ocular surface and collected in a $1.5 \mathrm{ml}$ Eppendorf tube containing DMEM. Samples were stored at $-80^{\circ} \mathrm{C}$. For virus quantification, a viral plaque assay was performed using Vero cells. Vero monolayers were prepared in 12 well tissue culture plates and incubated with 10-fold dilutions of each sample at room temperature (RT) for 1 hour with shaking. Cells were subsequently washed with complete medium and incubated with complete medium with $1 \%$ methyl cellulose for 3 days at $37^{\circ} \mathrm{C}$ with $5 \% \mathrm{CO}_{2}$ for viral plaque formation. Next, plates were washed, fixed using $10 \%$ formalin and stained with crystal 
violet. Viral plaques were counted using a light microscope and calculated according to the dilution factor.

\section{Neutralization Assay}

Mouse tears were collected using a sterile cotton swab and placed in a $1.5 \mathrm{ml}$ Eppendorf tube containing DMEM. Each sample represents a pool of 5 animals. Approximately 100 PFU of HSV1 (McKrae) was mixed with $0.5 \mathrm{ml}$ DMEM containing tears and incubated at $37^{\circ} \mathrm{C}$ for 1 hour for neutralization. After incubation, the mixture was placed on Vero monolayers on 12 well plates and incubated at room temperature with shaking. The plates were subsequently washed and incubated with complete medium with $1 \%$ methyl cellulose for 3 days at $37^{0} \mathrm{C}$ with $5 \% \mathrm{CO}_{2}$ for viral plaque formation.

\section{qPCR}

Following challenge with HSV-1(McKrae), TGs were collected at the time of euthanasia and kept frozen until analysis. On the day of analysis, TGs were thawed, and total DNA was collected using the Qiagen Blood and Tissue kit per manufacturer's instructions. HSV1 glycoprotein $\mathrm{D}(\mathrm{gD})$ was used as the target gene for quantification using the following primer-probe mixtures purchased from IDT; gD FP - 5'-GTCCGGAAACAACCCTACAA-3', gD RP - 5'-GCAT TCGGTGTACTCCATGA-3, and qPCR Probe - PrimeTime 5' 6FAM $^{\mathrm{TM}} / \mathrm{ZEN}^{\mathrm{TM}} / 3$ ' 5'-TTGGTTTCGGATGGGAGGCAACT-3' $\mathrm{IB}^{\circledR} \mathrm{FQ}$. For qPCR, the Prime time Gene Expression Master Mix (IDT) was used according to the manufacturer's instructions and the reaction was run using the 7900HT Fast Real-Time PCR System with the 384-Well Block Module. TGs from naïve animals were used to set cut-off values and the gD G-block (IDT) was used to create a standard curve.

\section{FTY720 Treatment}

To reduce $\mathrm{T}$ cell infiltration in the mouse eyes following infection, FTY720 (Millipore-Sigma) was applied topically to ocular surfaces. FTY720 was dissolved in water at $10 \mathrm{mg} / \mathrm{mL}$. One drop (approx. $10 \mu \mathrm{l}$ ) of this solution was then applied twice daily to the ocular surface one day before infection and continued until 10 DPI. Uninfected naïve mice were treated similarly as controls.

\section{Multiplex Immunoassay}

Whole mouse eyes were collected following euthanasia and immediately frozen using liquid nitrogen. On the day of the assay the eyes were pulverized using a mortar and pestle while frozen. The resulted homogenized tissue was weighed and dissolved in Tris-based lysis buffer (Thermofisher) supplemented with protease inhibitor for total protein extraction. For detecting cytokine and chemokine, the Cytokine \& Chemokine Convenience 26-Plex Mouse ProcartaPlex ${ }^{\mathrm{TM}}$ Panel 1 (Thermofisher) was used according to manufactures instructions and data was acquired using the Bioplex200 equipment.

\section{Statistical Analysis}

Statistical analysis was performed using GraphPad Prism 9 software. Survival analysis was performed using the log-rank test. For analysis between three groups one-way ANOVA and Kruskal-Wallis test were performed. To compare results between two groups, the Mann-Whitney test was utilized. The statistical significance level was set at $\mathrm{p}=0.05$.

\section{RESULTS}

\section{The HV-1(F) VC2 Live-Attenuated Vaccine Generates Robust and Durable Immune Responses in Mice}

The VC2 vaccine strain specifies the amino-terminal deletion of 39 amino acids of glycoprotein $\mathrm{K}$ ( $\mathrm{gK}$ ), which has been shown to prevent entry into neuronal axons as well as fusion of the virus with cellular plasma membranes, while the virus replicates efficiently because it can enter epithelial and other cells through endocytosis (21-23). To confirm that the VC2 vaccine strain that contains the $\mathrm{gK}$ and the UL20 amino terminal deletions cannot infect neuronal endings, travel to the TG and establish latency, mouse corneas of naïve mice were infected with $10^{6}$ PFU per eye after mild-scarification with either the HSV-1(F) parental wild-type virus or the VC2 vaccine strain. Both the parental HSV-1(F) and VC2 viruses were avirulent, since none of the mice succumbed to the infection. Two weeks post infection, the amount of viral DNA in the TGs was quantified by quantitative PCR. HSV-1(F) but not VC2 viral DNA was detected in ganglionic tissues indicating that VC2 was unable to reach the TGs and establish latency (Figure 1A).

Previously, we reported that VC2 intramuscular vaccination of mice generates robust protection against lethal ocular HSV-1 (McKrae) challenge (18). To assess whether this protective immune response is virus replication-dependent and sustained over time, we immunized mice with VC2 or Ultraviolet (UV)inactivated VC2 and challenged the mice ocularly with HSV-1 (McKrae) at 21 days or 8 months after the booster immunization. $\mathrm{VC} 2$ vaccinated mice were fully protected at both time points (Figures 1B, C), and there were no apparent ocular and/or systemic clinical disease symptoms observed (Figure 1D). In contrast, mice immunized with the UV-inactivated VC2 succumbed to the HSV-1 (McKrae) within 5 DPI and significant ocular damage was noted characterized by ocular inflammation and cornea damage (Figures 1D, E). Determination of the relative number of viral genomes in ganglionic tissues by qPCR revealed that a significantly higher level of viral DNA was present in the TG of UV-VC2 vaccinated animals compared to those vaccinated with VC2 (Figure 1F). This data suggests IM immunization with live attenuated VC2 generates a robust protection compared to vaccination with inactivated $\mathrm{VC} 2$ virions.

\section{Absence of Neutralizing Antibody on Ocular Surfaces of VC2-Vaccinated Mice}

Previously, we showed that VC2 prime-boost intramuscular immunization induces a strong systemic neutralizing antibody response (18). To assess the contribution of neutralizing antibody in the observed ocular protection against HSV-1 (McKrae) infection, tears from vaccinated mice with either the VC2 
A

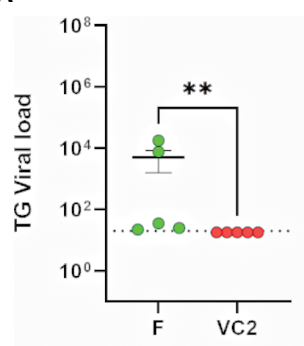

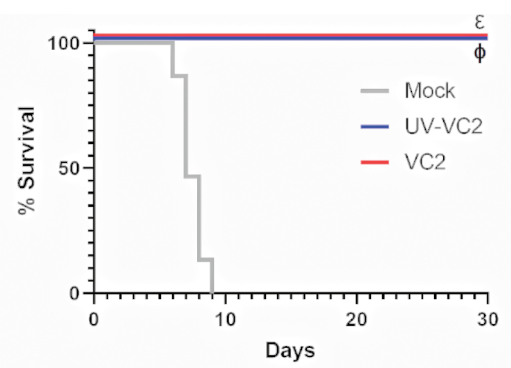

C

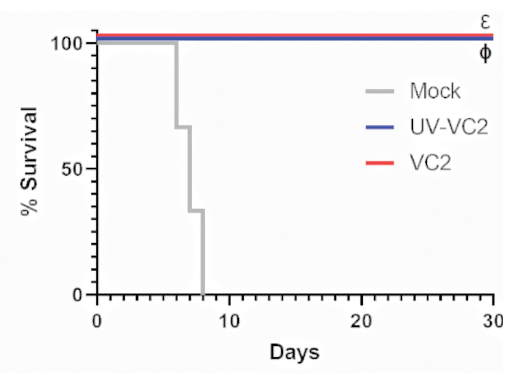

D

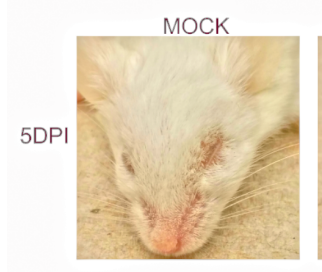

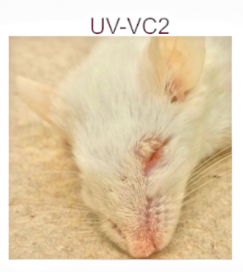

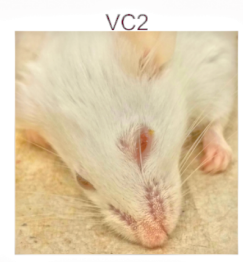

E

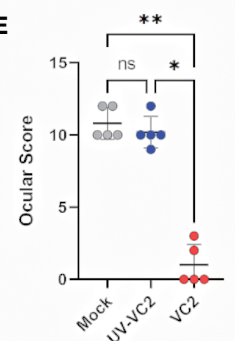

F

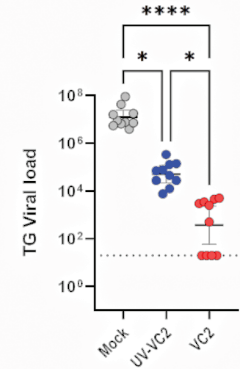

FIGURE 1 | Safety and protective efficacy of VC2 immunization in Balb/CJ mice against HSV-1 (McKrae strain) ocular challenge. (A) Mouse eyes were scarified and infected with HSV-1(F) or VC2 viruses at $10^{6}$ PFU per eye and viral loads in TGs were quantified by qPCR at 20 days post infection. (B) Kaplan-Meir survival curves of mice immunized with either, VC2, UV-irradiated VC2 or mock-immunized and challenged with HSV-1 (McKrae strain) at 21 days post booster immunization. The experiment was duplicated with $n=10 /$ group each time. (C) Kaplan-Meir survival curves as with (B) challenged with HSV-1 (McKrae strain) at 8 months post booster immunization, $n=10 /$ group. (D) Representative pictures of animals in each group at 5 DPI. (E) Ocular scores following challenge at 5 DPI. (F) Quantification of TG viral load following euthanasia. ${ }^{*}<\mathrm{P}=0.05,{ }^{*{ }^{* *} *}<\mathrm{P}=0.0001$ by One-Way ANOVA. ${ }^{*}<\mathrm{P}=0.05,{ }^{* *}<\mathrm{P}=0.005,{ }^{* \star * *}<\mathrm{P}=0.0001$. ns, Non-Significant.

vaccine, the UV-inactivated VC2, or mock-vaccinated mice prior to challenge were tested for the presence of neutralizing antibody using a plaque reduction neutralizing assay. Tears from VC2 and VC2-inactivated vaccinated animals did not have higher neutralizing ability compared to mock-vaccinated animals (Figure 2A), suggesting the absence of strong neutralizing antibody activity at ocular surfaces. Detection of viral antigens on FFPE sections by indirect immunofluorescence of ocular tissues with anti-HSV-1 polyclonal antibody revealed the presence of viral antigens on ocular surfaces at 2- and 5 DPI in all groups of animals (Figure 2B, green). In addition, transcription of the HSV-1 UL48 gene was detected in all ocular tissues using the RNAScope assay (Figure 2B, red dots). These results indicated productive infection and viral replication in all groups for at least 5DPI. However, at 5DPI viral shedding in VC2-vaccinated animals were undetectable compared to the mock and UV-VC2vaccinated mice (Figure 2C). This data suggests that despite productive infection and ocular viral replication, the VC2vaccinated animals experienced robust ocular mucosal responses that significantly reduced viral infection and resultant immunopathogenesis in the absence of neutralizing activity.

\section{Ocular Protection Is Associated With $\gamma \delta T$ Cell Infiltration}

To assess the extent of cell-mediated immunity at ocular surfaces following infection with HSV-1 (McKrae), immune cellular infiltration was evaluated at 2-, 5- and 9 DPI. No detectable differences were noted for macrophages, dendritic cells and NK cells infiltration at any time points (Figures 3A-C). A large neutrophil influx was noted following infection in mockvaccinated animals at 5DPI (Figure 1E). In contrast, VC2 vaccinated animals showed significantly lower neutrophil counts at 5DPI (Figures 3D-F). A significantly higher T cell infiltration was noted in VC2, but not in mock-vaccinated mice at 5DPI (Figures 3G-I). Further analysis revealed that the majority of the infiltrating $\mathrm{T}$ cells in all groups of mice expressed the gamma-delta $(\gamma \delta)$ TCR, while a relatively small population of CD4+, CD8+ and double negative TCR T cells were also present (Figures 3J-M). These results show that $\gamma \delta$ T cells were the dominant population of immune cells in vaccinated animals, while neutrophils were the major immune cell infiltrate in mock-vaccinated animals at 5DPI. Non-parametric Spearman correlation among all groups of mice revealed a negative correlation between $\gamma \delta \mathrm{T}$ cells and neutrophil accumulation in corneas at 5DPI among all groups (Figure 3N). The infiltrating $\gamma \delta \mathrm{T}$ cell numbers peaked at $9 \mathrm{DPI}$ and eventually dropped to basal levels at 25 DPI (after the resolution of ocular pathogenesis (Figure 3K). Importantly, the UV-VC2 vaccinated group of mice had lower $\gamma \delta \mathrm{T}$ cell accumulation and high neutrophil accumulation at 5DPI in comparison to the VC2vaccinated mice that correlated with the observed elevated ocular disease scores in UV-VC2 versus VC2-vaccinated mice (Figures 1E, 3E, H). 
A

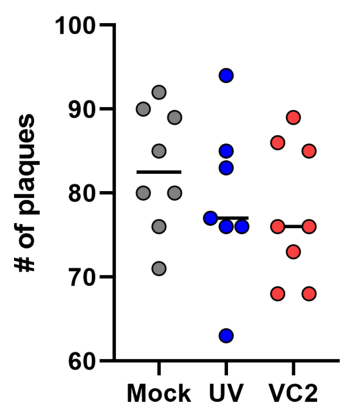

C

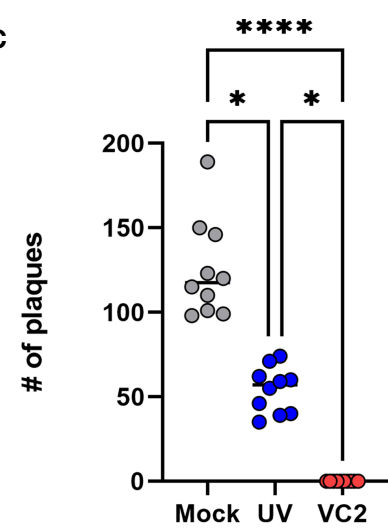

B
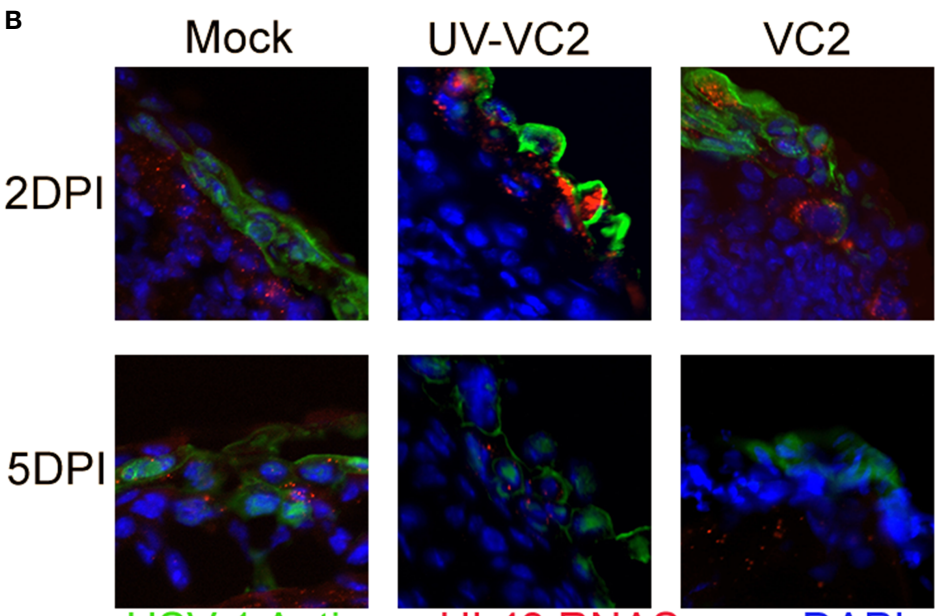

HSV-1 Antigen UL48 RNAScope DAPI

FIGURE 2 | Neutralizing antibodies in mouse tears and post-challenge viral replication in ocular tissues. (A) Neutralization of virus after the incubation with tear fluids. (B) Viral replication in ocular tissues following challenge at 2- \& 5DPI detected by IFM and RNAScope assays. Detection of viral antigens (green) HSV-1 UL48 transcripts (red). (C) Viral shedding on ocular surfaces quantified by plaque assay at 5DPI. ${ }^{*}<\mathrm{P}=0.05,{ }^{\star * \star *}<\mathrm{P}=0.0001$ by One-Way ANOVA.

To address whether the presence of $\gamma \delta \mathrm{T}$ cells following infection in VC2-vaccinated animals is the result of local proliferation or infiltration, a flow cytometry analysis for Ki67, a marker for cellular proliferation, was performed. Following infection, there was no significant increase of $\mathrm{Ki}^{+} 7^{+} \gamma \delta \mathrm{T}$ cells in VC2-vaccinated animals (Figure 30) suggesting that the presence of $\gamma \delta \mathrm{T}$ cell is due to the increased infiltration rather than local proliferation of resident $\gamma \delta \mathrm{T}$ cells. In addition, $\gamma \delta \mathrm{T}$ cells were detected by indirect immunofluorescence on OCT sections of ocular tissues in the corneal stroma of vaccinated animals with little to no neutrophil presence (Figure 3P, rightmost panel). In contrast, a high number of neutrophils were detected in the corneal stroma and epithelium in mockvaccinated animals, while low numbers of $\gamma \delta \mathrm{T}$ cells were also present (Figure 3P, left-most panel). Taken together, this data suggests VC2 vaccinated animals recruit $\gamma \delta \mathrm{T}$ cells following infection at the ocular surface and that increased neutrophil migration is prevented.

\section{Increase Lymphoangiogenesis and Reduced Neovascularization Is Associated With $\gamma \delta \mathrm{T}$ Cell Infiltration}

HSV-1 infection induces neovascularization following infection (46), and infiltrating immune cells may prolong neovascularization by secreting pro-angiogenic growth factors. This neovascularization is likely to be the source of increased levels of corneal neutrophils (47). To assess whether the VC2-vaccination affects neovascularization, OCT sections were stained for LYVE-1, a marker of lymphangiogenesis (48) and CD31, a marker of angiogenesis (49). HSV-1 infection in mock-vaccinated animals had high levels of CD31 expression (Figure 4, left panel) as also described previously $(46,49)$. In contrast, VC2-vaccinated animals exhibited strong reactivity with the anti-LYVE-1 antibody, while little or no CD31 expression was detectable in the cornea (Figure 4, right panel). This data suggests that neovascularization is not responsible for the higher infiltrating $\gamma \delta \mathrm{T}$ cells in VC2 immunized mice. 
A

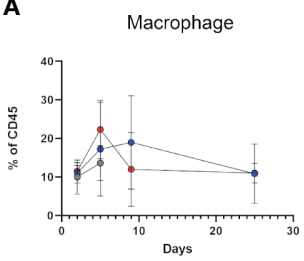

D

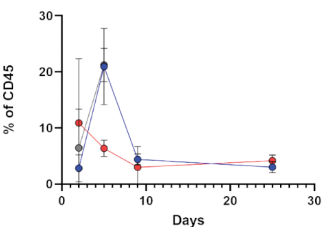

G

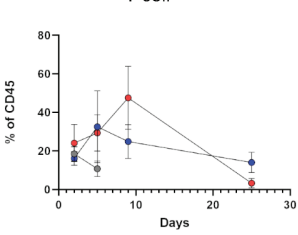

$\mathbf{K}$
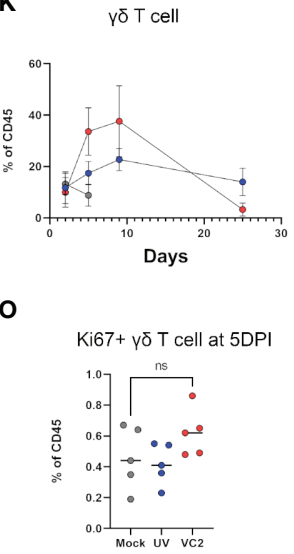

B

Dendritic Cells

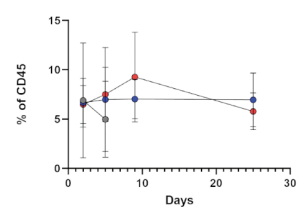

E

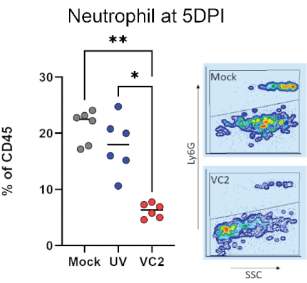

H

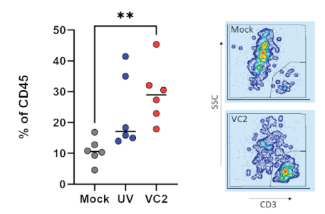

L

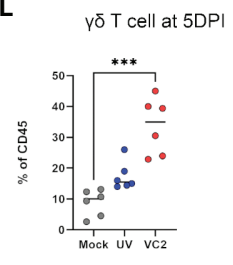

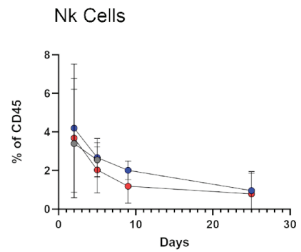

$\mathbf{F}$ Neutrophil at 5DPI

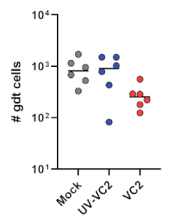

I $T$ cell at 5DP J T cell population
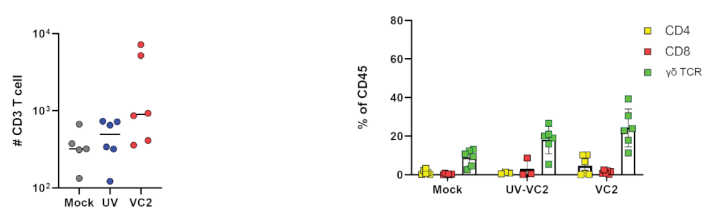

N

M

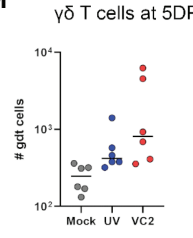

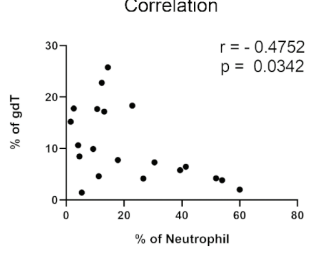

$\mathbf{P}$
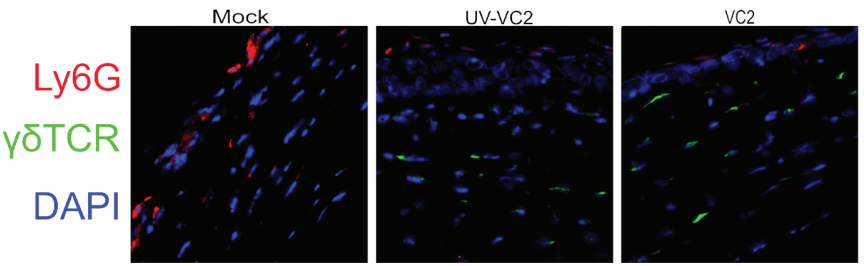

FIGURE 3 | Phenotype of cellular infiltrates in ocular tissues following viral challenge. Flow cytometric analysis for cellular infiltration for: (A) Macrophage. (B) Dendritic cells. (C) NK cells over time. (D) Percentage of neutrophil accumulation over time. (E, F) Percentage and absolute count of neutrophils at 5DPI. (G) Percentage of T cell accumulation over time. (H, I) Percentage and absolute count of T cells. (J) Phenotype of T cells in individual groups. $\gamma \delta$ T cell accumulation over time (K), percentage (L) and absolute count (M) at 5DPI. (N) Spearman's rank correlation between $\gamma \delta$ T cell and neutrophil accumulation among all groups. (0) Ki67+ $\gamma \delta \mathrm{T}$ cell in cornea. (P) IFM for the presence of neutrophils and $\gamma \delta \mathrm{T}$ using OCT section. ${ }^{* *}<\mathrm{P}=0.005,{ }^{* * *}<\mathrm{P}=0.001$ using One-Way ANOVA, $\mathrm{n}=6 /$ group/timepoint.

\section{Increased Levels of IL-4 and IL-22 Is Associated With Protection}

To address the status of immune response, we used a 26 plex immunoassay to detect Th1/Th2Th9/Th17Th22 and Treg associated cytokines and chemokines in homogenized eye samples at 5 DPI. The VC2 and UV-VC2 vaccinated animals exhibited a unique cytokine and chemokine expression profile compared to the mock-vaccinated animals. Specifically, the VC2 and UV-VC2 immunized animals had significantly higher IL-4 and IL-22 levels in the eye (Figures 5A, B). In contrast, the proinflammatory cytokine IL-5 and chemokine Gro-alpha/KC, IP10 and MCP-1 was detected at lower levels in VC2 and UV-VC2 immunized animals compared to mock-vaccinated animals (Figures 5C-F). It has been reported that these proinflammatory cytokines are associated with tissue damage, neutrophil accumulation and increased severity of HSV-1 infection $(47,50)$. Overall, this data suggests VC2 immunization generates a unique adaptive response that 

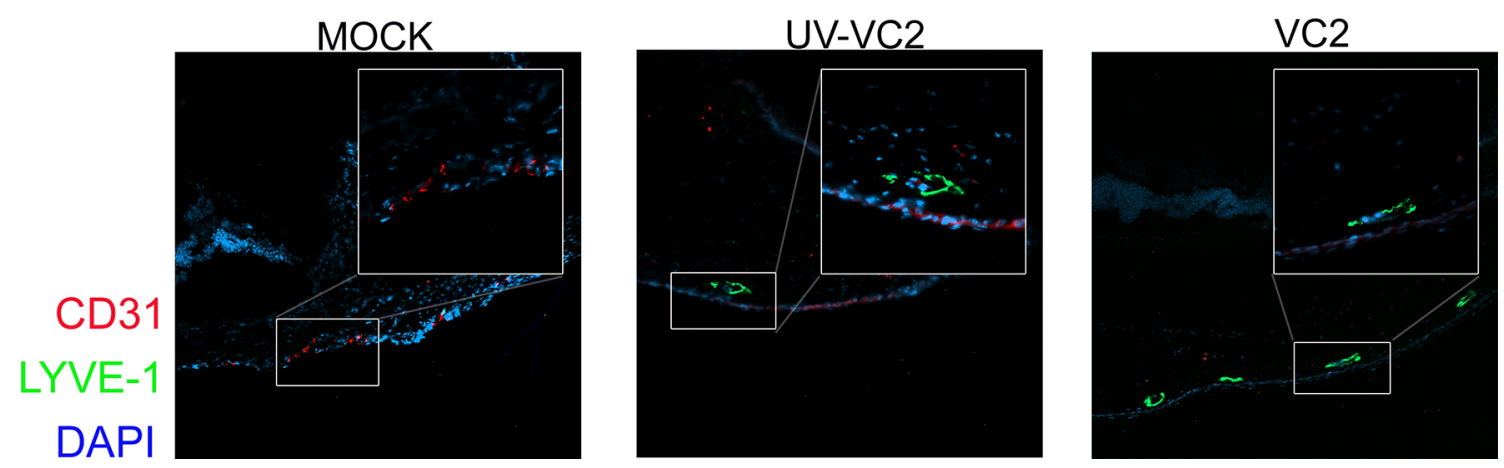

FIGURE 4 | Neovascularization and lymph-angiogenesis in ocular tissues. IFM on OCT sections was used to detect the presence of neovascularization (CD31-red) and lymph-angiogenesis (LYE-1 green).

A

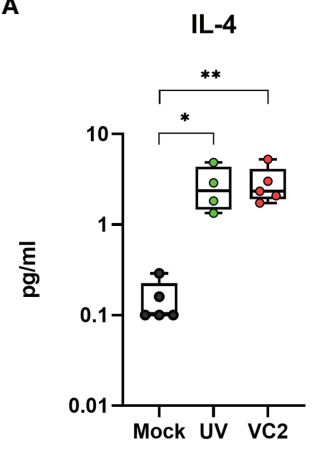

D

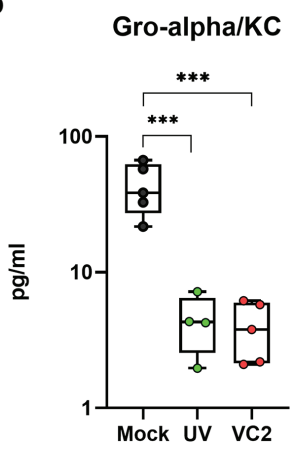

B
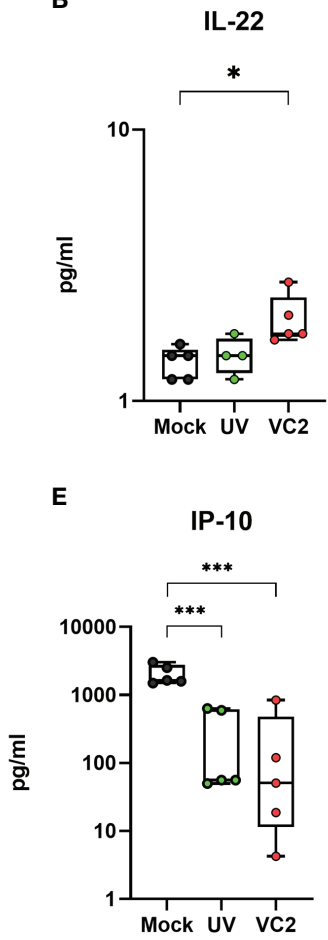

C

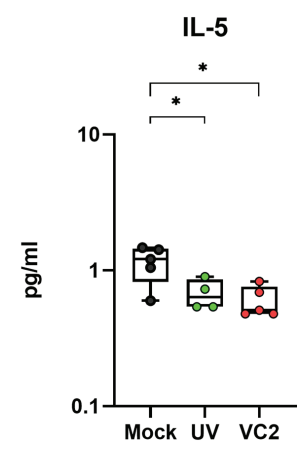

$\mathbf{F}$

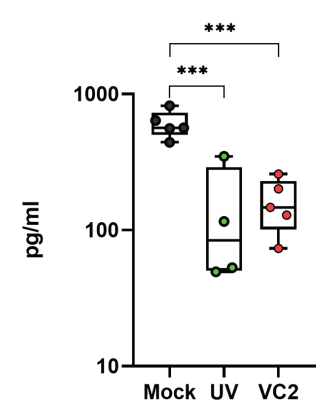

FIGURE 5 | Pro-inflammatory and anti-inflammatory cytokines and chemokines in whole eye tissues. Cytokine IL-4, IL-22 and IL-5 (A-C), and chemokine Groalpha/KC, IP-10 and MCP-1 (D-F) were measured from homogenized eye samples using the 26 plex immunoassay kit. ${ }^{*}<P=0.05,{ }^{* *}<P=0.005,{ }^{\star \star *}<P=0.001$ using One-Way ANOVA, $n=5 /$ group.

reduces pro-inflammatory signals and that this reduction is associated with infiltrating $\gamma \delta \mathrm{T}$ cells.

\section{Infiltrating $\gamma \delta \mathrm{T}$ Cells Do Not Originate From an HSV-1 Specific Memory Population}

Several studies suggested that $\gamma \delta \mathrm{T}$ cells may contain memory populations like $\alpha \beta T$ cells and can undergo memory-like expansion following antigen recognition (51-56). To address the possibility of whether infiltrating $\gamma \delta \mathrm{T}$ cells represent an HSV-
1 specific memory population, we performed a BrdU proliferation experiment in-vivo. Both mock and VC2vaccinated animals were administered $1 \mathrm{ml}$ concentrated BrdU per $100 \mathrm{~g}$ body weight via the intraperitoneal route one day before infection and continued every day. Following euthanasia, both eyes were removed and mLN cells were stained for BrdU positive cells. VC2-vaccinated animals exhibited marked incorporation (red) of BrdU in B (CD19), CD4 and CD8 T cells in mLN at 5DPI compared to mock-vaccinated (gray) 
animals, suggesting a pre-existing memory population for these cells (Figure 6A). However, there was no significant difference detected for BrdU-positive $\gamma \delta \mathrm{T}$ cells in $\mathrm{mLN}$ tissues (Figure 6A, right panel), indicating the absence of a memory population. In addition, BrdU positive $\gamma \delta \mathrm{T}$ cells in the vaccinated animals did not have a higher frequency of T central memory (TCM CD44+ $\mathrm{CD} 62 \mathrm{~L}$ ) as BrdU positive CD4+ and CD8+ T cells (Figure 6B) suggesting the absence of TCM in the proliferating $\gamma \delta \mathrm{T}$ cell population. Further, there was no difference in BrdU-positive $\gamma \delta \mathrm{T}$ cell in the ocular mucosa tissues following infection and only a small percentage of $\gamma \delta \mathrm{T}$ were BrdU-positive in both mock and VC2-vaccinated groups (Figure 6C) suggesting infiltration of pre-existing rather than newly proliferative $\gamma \delta$ T cells in the eye following infection. Taken together, our data strongly suggest that the infiltrating $\gamma \delta \mathrm{T}$ cells in vaccinated animals were not
HSV-1 specific/experienced memory populations, but rather non-specific $\gamma \delta \mathrm{T}$ cells recruited in the infected cornea in vaccinated animals with increased frequency.

\section{$\gamma \delta \mathrm{T}$ Cell Infiltration Is Required to Control Ocular Immunopathogenesis}

Although it has been reported that $\gamma \delta \mathrm{T}$ cells have an important role on the mucosal surface (57-60), the role of the $\gamma \delta \mathrm{T}$ cells in vaccine-induced protection against herpes ocular immunopathogenesis and specifically herpes keratitis has not been investigated. The association of $\gamma \delta \mathrm{T}$ cell infiltration (Figure 3K) and lower ocular damage (Figure 1E) suggest a functional role of this infiltrating population on corneal pathology following infection. This raises the question of whether the presence of this population is necessary for the

\section{A}
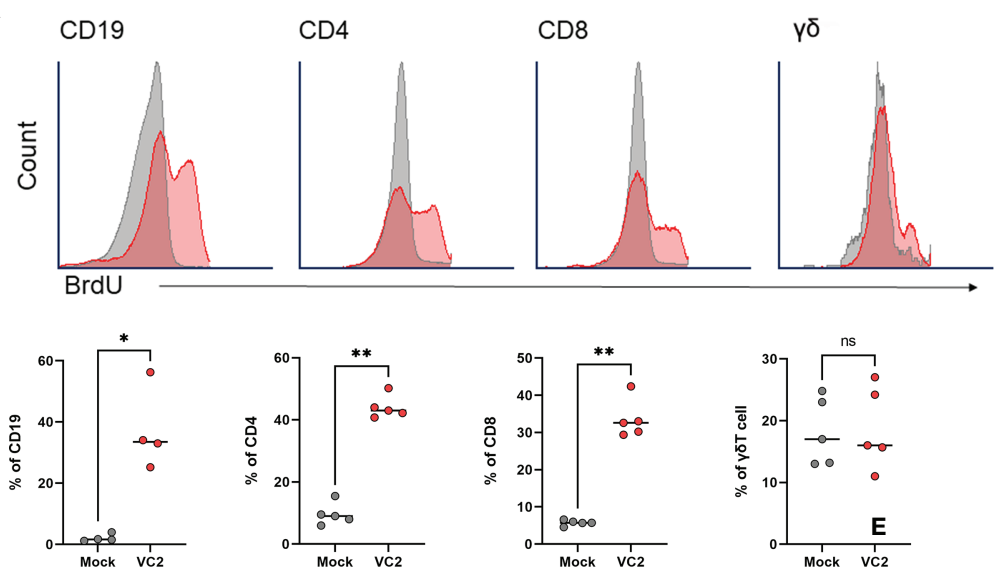

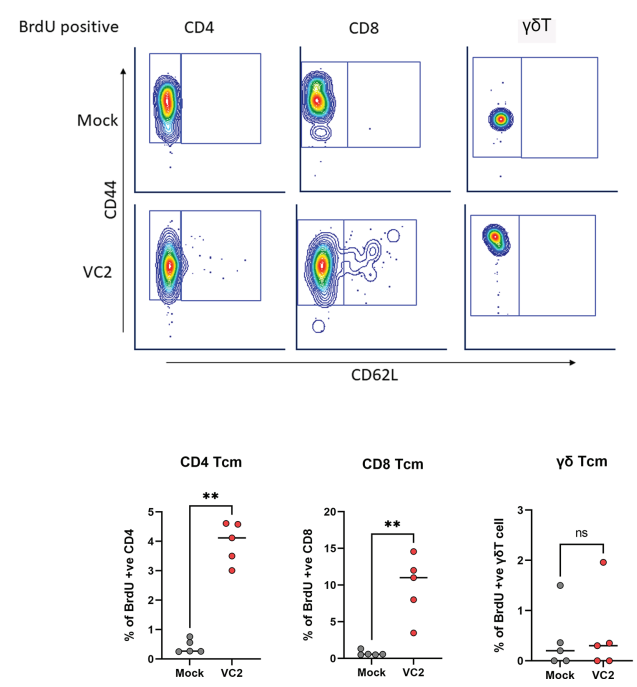

C

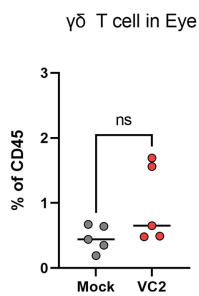

FIGURE 6 | Analysis of antigen-specific memory T cell expansion in LN at 5DPI. (A) Representative histogram (top panel) and percentage of BrdU incorporation in CD19, CD4, CD8 and $\gamma \delta$ T cells in $\mathrm{mLN}$ cells using flow cytometry (bottom panel). (B) Representative gating (Top panel) and percentage of BrdU-positive TCM in CD4, CD8 and $\gamma \delta$ T cell populations. (C) Percentage of BrdU-positive $\gamma \delta$ T cell in the eye following infection. ${ }^{*}<P=0.05$, ${ }^{*}<P=0.005$ using Mann-Whitney test, $n=5 / g r o u p . ~ n s$, Non-Significant. 
control of HSV-1 induced keratitis in vaccinated animals. Unfortunately, there is neither a $\gamma \delta \mathrm{T}$ cell $\mathrm{KO}$ animal in the Balb/C background nor an appropriate depleting antibody to remove this cell type from systemic and peripheral circulation to study the specific role of $\gamma \delta$ T cells following HSV-1 challenge. To circumvent this issue, we used FTY720 (Fingolimod, Sigma), an FDA-approved drug for immune suppression, which inhibits lymphocyte egress from both thymus and secondary lymphoid organs (61). Following infection in vaccinated animals, 1 drop (approximately $10 \mu \mathrm{l}$ ) of FTY720 $(10 \mathrm{mg} / \mathrm{ml})$ was applied twice daily topically to the mouse eyes to prevent $\mathrm{T}$ cell infiltration. Because FTY720 was applied directly to the ocular surface, it was unlikely to alter cellular migration in other tissues. As expected, the FTY720 treatment lowered $\gamma \delta \mathrm{T}$ cell infiltration at 5 DPI
(Figure 7A). At the same time, FTY720-treated vaccinated animals exhibited a significant increase in neutrophil infiltration (Figure 7B) and concomitant increased ocular disease score (Figure 7C) compared to the PBS-treated and vaccinated animals. To confirm that FTY720 treatment did not increase ocular scores, naïve animals were also treated with FTY720 and showed minimal ocular damage in the absence of infection (Figure 7C, green). Further, there was no substantial increase in viral shedding in VC2-vaccinated animals compared to PBS-treated animals (data not shown) suggesting that the observed ocular damage is not due to persistent viral replication, but rather the result of increased neutrophil infiltration. The ocular damage persisted (gross observations) as long as the FTY720 treatment continued, and animals recovered quickly

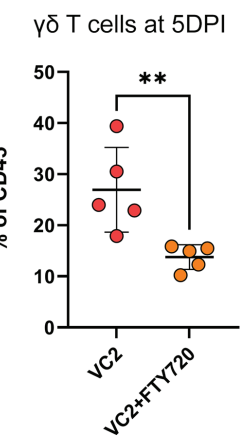

B

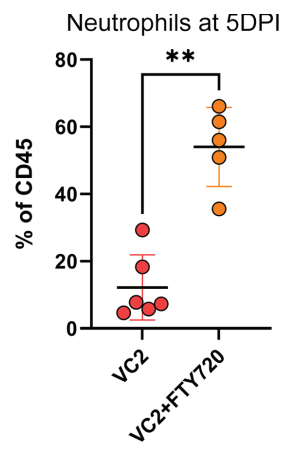

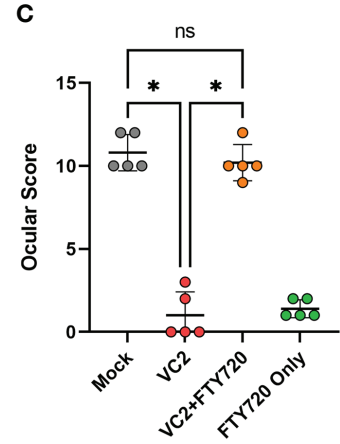

D

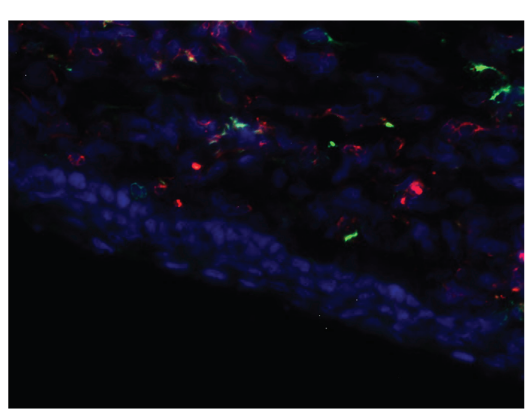

Ly6G үסTCR DAPI

E

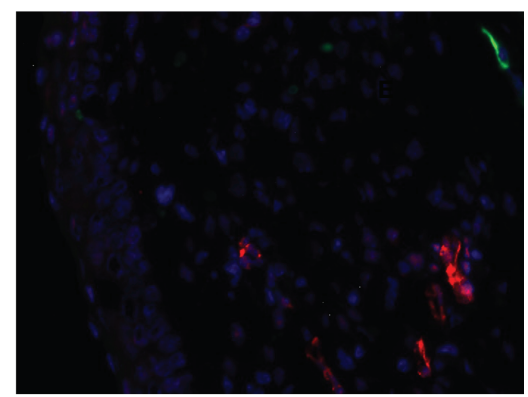

LYVE-1 CD31 DAPI

F

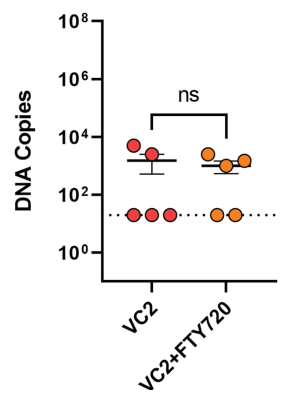

FIGURE 7 | Ocular infiltration and score following inhibition of T cell migration. T cell migration in mouse eyes was inhibited by the administration of FTY720 on ocular surfaces. (A) $\gamma \delta \mathrm{T}$ cell infiltration. (B) Neutrophil infiltration at 5DPI. (C) Ocular score following infection. (D) IFM on a representative OCT section for detection of $\gamma \delta \mathrm{T}$ and neutrophil cell infiltration in ocular tissues. (E) IFM for CD31 and LYVE-1 expression. (F) Viral DNA copies in TG using $\mathrm{qPCR}$. ${ }^{*}<\mathrm{P}=0.05$, ${ }^{* *}<\mathrm{P}=0.005$ using the Mann-Whitney test, $n=5 /$ group. ns, Non-Significant. 
after FTY720 treatment termination (data not shown). Increased neutrophil infiltration (Figure 7D) and neovascularization (Figure 7E) was also detected more frequently after the challenge in FTY720-treated vaccinated animals. Although FTY720 treatment following challenge in vaccinated animals increased ocular pathogenesis, it did not have any effect on survival (data not shown), as well as on viral loads in the TG tissues (Figure 7F) suggesting that the role of $\gamma \delta \mathrm{T}$ cell accumulation is limited to control of ocular immunopathogenesis induced by HSV-1 infection.

\section{DISCUSSION}

An over-active immune system during HSV-1 infection is generally thought to be the principal cause of corneal tissue damage (6). This damage is attributed to the influx of neutrophils $(40,41)$ and CD4 T cells that lead to visual impairment $(4,62)$. However, these cell populations have also been shown to be beneficial since their depletion rendered the animals more susceptible to infection. Thus, a balanced immune response is required to protect ocular tissues from immune-mediated damage, while ensuring clearance of the viral infection. We recently showed that the live-attenuated VC2 vaccine, which cannot enter neuronal axons and establish latency, protects mice against lethal ocular HSV-1 challenge and the development of HK (18). Herein, we show that VC2 intramuscular vaccination of mice results in $\gamma \delta \mathrm{T}$ cell enhanced accumulation and reduction of infiltration neutrophils that results in substantial reduction of HSV ocular immunopathogenesis.

$\gamma \delta \mathrm{T}$ cells are known to participate in innate and adaptive immune responses (63-65). These cells can respond quickly to bacterial and viral infections because they can be activated by cytokines and toll-like receptor (TLR) signals without the need for $\mathrm{T}$ cell antigen receptor (TCR) activation $(64,66-68)$. This dual nature of $\gamma \delta \mathrm{T}$ cell biology is due to their non-MHC-restricted antigenic specificity enabling them to respond to a variety of cellular stress signals $(69,70) . \gamma \delta$ T cells are present in lymphoid tissues and the blood in adult humans and rodents at low frequencies; however, they are enriched in epithelial and mucosal tissues. Tissue-specific $\gamma \delta \mathrm{T}$ cells are differentiated in various $\mathrm{T}$ cell subsets possessing specific functions acting as sensors of invading pathogens (71-74). In addition, a number of cytokines and chemokines are secreted by $\gamma \delta \mathrm{T}$ cells that can affect overall immune responses and tissue repair and healing (75). Several reports suggest that $\gamma \delta \mathrm{T}$ cells are involved in mucosal immunity against several pathogens, although the mechanism may vary widely $(51,57-60,76,77)$. Previously, the presence of $\gamma \delta \mathrm{T}$ cells in the cornea of naïve mice infected ocularly with virulent HSV-1 was shown to be essential for protection against viral infection and resultant immunopathogenesis. Protection was associated with infiltration of $\gamma \delta$ T CCR6 positive cells from the lymphatic system $(78,79)$. Our results agree with these findings. Specifically, we found that the $\gamma \delta \mathrm{T}$ cell population was prominent in mock-vaccinated animals. However, we observed a drastic increase of $\gamma \delta \mathrm{T}$ cell infiltration into the infected corneas as the result of VC2 intramuscular vaccination in comparison to mock-immunized animals suggesting that VC2 intramuscular immunization significantly altered the chemotactic movement of these cells from the lymphatic system into the infected corneas resulting in protection against virus-induced immunopathogenesis.

Several reports suggest that $\gamma \delta \mathrm{T}$ cells are involved in mucosal immunity and exhibit cytotoxic, tissue repair, and regulatory functions $(59,60,77,80-83)$. Specifically, several studies found that $\gamma \delta \mathrm{T}$ cells are involved in protection during ocular damage $(60,84-88)$. FTY720 mediated inhibition of $\gamma \delta \mathrm{T}$ cell accumulation in the corneas of vaccinated mice significantly increased virus-induced immunopathogenesis. This suggests that the observed $\gamma \delta \mathrm{T}$ cell accumulation is necessary to control exacerbated immune cell cytotoxicity, although the exact mechanism is not clear at present. It is worth noting that the reduction of neutrophil infiltration into the corneas of VC2vaccinated animals was associated with the concurrent increase of $\gamma \delta \mathrm{T}$ cells, since the absolute number of neutrophils was lower in vaccinated versus mock-vaccinated animals (Figure 3F). In addition, neutrophil numbers increased in the absence of $\gamma \delta \mathrm{T}$ cells when VC2-vaccinated animals were treated with FTY720. This result suggests that $\gamma \delta \mathrm{T}$ cells reduce tissue damage by inhibiting the recruitment of neutrophils into the infected corneal tissues from the systemic circulation. The expression of several cytokines was noted to be drastically different in VC2vaccinated animals characterized by significant increases of IL-4, IL-22, and reduction of the inflammatory cytokine IL-5. Although $\gamma \delta$ T cells have been reported to secrete mainly IFN $\gamma$ and IL-17, there are reports that these cells can also be a source of IL-4 $(89,90)$ and IL-22 (85). Both IL-4 and Il-22 were found to be involved in tissue repair (91-93). Future research should determine if $\gamma \delta \mathrm{T}$ cells are the source of these cytokines and whether they are involved in tissue repair during HK.

Several studies proposed the presence of memory phenotypes in $\gamma \delta \mathrm{T}$ cell populations and their expansion following infection (51-56, 81, 94). However, the BrdU proliferation assay (Figure 6) suggests that the $\gamma \delta \mathrm{T}$ cell accumulation in the cornea did not represent proliferation of tissue-specific cells, but infiltration of cells originating from proximal lymph nodes. We hypothesize that VC2 induces HSV-1-specific tissue-resident memory (TRM) cells on the cornea of vaccinated animals, which recognize HSV-1 following infection and recruit $\gamma \delta \mathrm{T}$ cells from the lymphatic system. It has been reported that gB498-505 epitope-specific TRM cells with $\mathrm{CD} 73^{+} \mathrm{CD} 8^{+}$phenotype accumulated in mouse eyes following low-dose HSV-1 infection (95). We noted that uninfected Balb/CJ mice had a very limited number of $\mathrm{T}$ cells residing in their corneas including both $\gamma \delta \mathrm{T}$ cell positive and negative populations. Tissue-residentmemory CD8+ $\mathrm{T}$ cells are known to bridge innate immune responses in neighboring cells and may be responsible for the observed $\gamma \delta \mathrm{T}$ cell accumulation. Alternatively, there may be a HSV- 1 specific $\gamma \delta$-TRM population residing in corneas that can efficiently recognize HSV-1 infection and recruit more $\gamma \delta \mathrm{T}$ cells at the site of infection. Both cell types may exist at low abundance, rendering difficult an assessment of their phenotypic and functional properties. 
Overall, our results strongly suggest that intramuscular immunization of mice with the live-attenuated $\mathrm{VC} 2$ vaccine strain significantly alters the infiltration of $\gamma \delta \mathrm{T}$ cells in the corneas of ocularly-challenged mice. These results suggest that a vaccinegenerated tissue-specific memory response results in significant protection against HSV-1 immunopathogenesis. The mechanism by which VC2-intramuscular immunization results into the observed tissue-specific response is currently under investigation.

\section{DATA AVAILABILITY STATEMENT}

The raw data supporting the conclusions of this article will be made available by the authors, without undue reservation.

\section{ETHICS STATEMENT}

The animal study was reviewed and approved by the Institutional Animal Care and Use Committee (IACUC), Louisiana State University, School of Veterinary Medicine.

\section{AUTHOR CONTRIBUTIONS}

$\mathrm{RN}$ and $\mathrm{KK}$ formulated and designed the study, analyzed and interpreted the data, and led the writing of the manuscript. AL evaluated all ocular infection results. VC constructed and verified all viruses used in this study. TC participated in the titration of different viruses and in viral neutralization experiments. $\mathrm{RN}$ and

\section{REFERENCES}

1. Smith JS, Robinson NJ. Age-Specific Prevalence of Infection With Herpes Simplex Virus Types 2 and 1: A Global Review. J Infect Dis (2002) 186(Suppl 1):S3-28. doi: 10.1086/343739

2. Bradley H, Markowitz LE, Gibson T, McQuillan GM. Seroprevalence of Herpes Simplex Virus Types 1 and 2-United States, 1999-2010. J Infect Dis (2014) 209(3):325-33. doi: 10.1093/infdis/jit458

3. Kasubi MJ, Nilsen A, Marsden HS, Bergstrom T, Langeland N, Haarr L. Prevalence of Antibodies Against Herpes Simplex Virus Types 1 and 2 in Children and Young People in an Urban Region in Tanzania. J Clin Microbiol (2006) 44(8):2801-7. doi: 10.1128/JCM.00180-06

4. Koujah L, Suryawanshi RK, Shukla D. Pathological Processes Activated by Herpes Simplex Virus-1 (HSV-1) Infection in the Cornea. Cell Mol Life Sci (2019) 76(3):405-19. doi: 10.1007/s00018-018-2938-1

5. Toma HS, Murina AT, Areaux RGJr., Neumann DM, Bhattacharjee PS, Foster TP, et al. Ocular HSV-1 Latency, Reactivation and Recurrent Disease. Semin Ophthalmol (2008) 23(4):249-73. doi: 10.1080/08820530802111085

6. Lobo AM, Agelidis AM, Shukla D. Pathogenesis of Herpes Simplex Keratitis: The Host Cell Response and Ocular Surface Sequelae to Infection and Inflammation. Ocul Surf (2018). doi: 10.1016/j.jtos.2018.10.002

7. Rowe AM, St Leger AJ, Jeon S, Dhaliwal DK, Knickelbein JE, Hendricks RL. Herpes Keratitis. Prog Retin Eye Res (2013) 32:88-101. doi: 10.1016/ j.preteyeres.2012.08.002

8. Shimeld C, Hill TJ, Blyth WA, Easty DL. Reactivation of Latent Infection and Induction of Recurrent Herpetic Eye Disease in Mice. J Gen Virol (1990) 71:397-404. doi: 10.1099/0022-1317-71-2-397

9. Fukuda M, Deai T, Higaki S, Hayashi K, Shimomura Y. Presence of a Large Amount of Herpes Simplex Virus Genome in Tear Fluid of Herpetic Stromal Keratitis and Persistent Epithelial Defect Patients. Semin Ophthalmol (2008) 23(4):217-20. doi: 10.1080/08820530802111366
TC performed statistical analysis. All authors contributed to the article, critically reviewed and approved the submitted version.

\section{FUNDING}

The work was supported by funds of the LSU Division of Biotechnology \& Molecular Medicine (BioMMED), School of Veterinary Medicine, by a Governor's Biotechnology Initiative grant from the Louisiana Board of Regents (to KK), and by Cores of the Center for Experimental Infectious Disease Research (CEIDR) and Louisiana Biomedical Research Network (LBRN) supported by NIH: NIGMS P30GM110670 and P20GM103424, respectively.

\section{ACKNOWLEDGMENTS}

We thank coordinators and staff of the Division of Biotechnology \& Molecular Medicine (BioMMED) of the LSU School of Veterinary Medicine for assisting in making this study possible.

\section{SUPPLEMENTARY MATERIAL}

The Supplementary Material for this article can be found online at: https://www.frontiersin.org/articles/10.3389/fimmu.2021. 789454/full\#supplementary-material

Supplementary Figure 1 | Gating strategy.

10. Paludan SR, Bowie AG, Horan KA, Fitzgerald KA. Recognition of Herpesviruses by the Innate Immune System. Nat Rev Immunol (2011) 11 (2):143-54. doi: 10.1038/nri2937

11. Carr DJJ, Gmyrek GB, Filiberti A, Berube AN, Browne WP, Gudgel BM, et al. Distinguishing Features of High- and Low-Dose Vaccine Against Ocular HSV1 Infection Correlates With Recognition of Specific HSV-1-Encoded Proteins. Immunohorizons (2020) 4(10):608-26. doi: 10.4049/immunohorizons.2000060

12. Royer DJ, Hendrix JF, Larabee CM, Reagan AM, Sjoelund VH, Robertson DM, et al. Vaccine-Induced Antibodies Target Sequestered Viral Antigens to Prevent Ocular HSV-1 Pathogenesis, Preserve Vision, and Preempt Productive Neuronal Infection. Mucosal Immunol (2019) 12(3):827-39. doi: 10.1038/s41385-019-0131-y

13. Burn C, Ramsey N, Garforth SJ, Almo S, Jacobs WRJr., Herold BC. A Herpes Simplex Virus (HSV)-2 Single-Cycle Candidate Vaccine Deleted in Glycoprotein D Protects Male Mice From Lethal Skin Challenge With Clinical Isolates of HSV-1 and HSV-2. J Infect Dis (2018) 217(5):754-8. doi: 10.1093/infdis/jix628

14. Royer DJ, Gurung HR, Jinkins JK, Geltz JJ, Wu JL, Halford WP, et al. A Highly Efficacious Herpes Simplex Virus 1 Vaccine Blocks Viral Pathogenesis and Prevents Corneal Immunopathology via Humoral Immunity. J Virol (2016) 90(11):5514-29. doi: 10.1128/JVI.00517-16

15. Chiuppesi F, Vannucci L, De Luca A, Lai M, Matteoli B, Freer G, et al. A Lentiviral Vector-Based, Herpes Simplex Virus 1 (HSV-1) Glycoprotein B Vaccine Affords Cross-Protection Against HSV-1 and HSV-2 Genital Infections. J Virol (2012) 86(12):6563-74. doi: 10.1128/JVI.00302-12

16. $\mathrm{Hu} \mathrm{K}, \mathrm{He} \mathrm{X}, \mathrm{Yu} \mathrm{F}, \mathrm{Yuan} \mathrm{X}, \mathrm{Hu} \mathrm{W}$, Liu C, et al. Immunization With DNA Vaccine Expressing Herpes Simplex Virus Type $1 \mathrm{gD}$ and IL-21 Protects Against Mouse Herpes Keratitis. Immunol Invest (2011) 40(3):265-78. doi: 10.3109/08820139.2010.534219

17. Awasthi S, Lubinski JM, Friedman HM. Immunization With HSV-1 Glycoprotein C Prevents Immune Evasion From Complement and 
Enhances the Efficacy of an HSV-1 Glycoprotein D Subunit Vaccine. Vaccine (2009) 27(49):6845-53. doi: 10.1016/j.vaccine.2009.09.017

18. Naidu SK, Nabi R, Cheemarla NR, Stanfield BA, Rider PJ, Jambunathan N, et al. Intramuscular Vaccination of Mice With the Human Herpes Simplex Virus Type-1(HSV-1) VC2 Vaccine, But Not its Parental Strain HSV-1(F) Confers Full Protection Against Lethal Ocular HSV-1 (McKrae) Pathogenesis. PloS One (2020) 15(2):e0228252. doi: 10.1371/journal.pone.0228252

19. Stanfield BA, Rider PJF, Caskey J, Del Piero F, Kousoulas KG. Intramuscular Vaccination of Guinea Pigs With the Live-Attenuated Human Herpes Simplex Vaccine VC2 Stimulates a Transcriptional Profile of Vaginal Th17 and Regulatory Tr1 Responses. Vaccine (2018) 36(20):2842-9. doi: 10.1016/ j.vaccine.2018.03.075

20. Stanfield BA, Stahl J, Chouljenko VN, Subramanian R, Charles AS, Saied AA, et al. A Single Intramuscular Vaccination of Mice With the HSV-1 VC2 Virus With Mutations in the Glycoprotein K and the Membrane Protein UL20 Confers Full Protection Against Lethal Intravaginal Challenge With Virulent HSV-1 and HSV-2 Strains. PloS One (2014) 9(10):e109890. doi: 10.1371/ journal.pone. 0109890

21. Saied AA, Chouljenko VN, Subramanian R, Kousoulas KG. A Replication Competent HSV-1(McKrae) With a Mutation in the Amino-Terminus of Glycoprotein K (Gk) is Unable to Infect Mouse Trigeminal Ganglia After Cornea Infection. Curr Eye Res (2014) 39(6):596-603. doi: 10.3109/ 02713683.2013 .855238

22. Jambunathan N, Charles AS, Subramanian R, Saied AA, Naderi M, Rider P, et al. Deletion of a Predicted Beta-Sheet Domain Within the Amino Terminus of Herpes Simplex Virus Glycoprotein K Conserved Among Alphaherpesviruses Prevents Virus Entry Into Neuronal Axons. J Virol (2015) 90(5):2230-9. doi: 10.1128/JVI.02468-15

23. Musarrat F, Jambunathan N, Rider PJF, Chouljenko VN, Kousoulas KG. The Amino Terminus of Herpes Simplex Virus 1 Glycoprotein K (Gk) Is Required for gB Binding to Akt, Release of Intracellular Calcium, and Fusion of the Viral Envelope With Plasma Membranes. J Virol (2018) 92(6):e01842-17. doi: 10.1128/JVI.01842-17

24. Chouljenko VN, Iyer AV, Chowdhury S, Kim J, Kousoulas KG. The Herpes Simplex Virus Type 1 UL20 Protein and the Amino Terminus of Glycoprotein K (Gk) Physically Interact With Gb. J Virol (2010) 84(17):8596-606. doi: 10.1128/JVI.00298-10

25. Foster TP, Chouljenko VN, Kousoulas KG. Functional and Physical Interactions of the Herpes Simplex Virus Type 1 UL20 Membrane Protein With Glycoprotein K. J Virol (2008) 82(13):6310-23. doi: 10.1128/ JVI.00147-08

26. Foster TP, Melancon JM, Baines JD, Kousoulas KG. The Herpes Simplex Virus Type 1 UL20 Protein Modulates Membrane Fusion Events During Cytoplasmic Virion Morphogenesis and Virus-Induced Cell Fusion. J Virol (2004) 78(10):5347-57. doi: 10.1128/JVI.78.10.5347-5357.2004

27. Foster TP, Melancon JM, Olivier TL, Kousoulas KG. Herpes Simplex Virus Type 1 Glycoprotein $\mathrm{K}$ and the UL20 Protein are Interdependent for Intracellular Trafficking and Trans-Golgi Network Localization. J Virol (2004) 78(23):13262-77. doi: 10.1128/JVI.78.23.13262-13277.2004

28. Melancon JM, Foster TP, Kousoulas KG. Genetic Analysis of the Herpes Simplex Virus Type 1 UL20 Protein Domains Involved in Cytoplasmic Virion Envelopment and Virus-Induced Cell Fusion. J Virol (2004) 78(14):7329-43. doi: 10.1128/JVI.78.14.7329-7343.2004

29. Melancon JM, Fulmer PA, Kousoulas KG. The Herpes Simplex Virus UL20 Protein Functions in Glycoprotein K (Gk) Intracellular Transport and VirusInduced Cell Fusion Are Independent of UL20 Functions in Cytoplasmic Virion Envelopment. Virol J (2007) 4:120. doi: 10.1186/1743-422X-4-120

30. Chouljenko VN, Iyer AV, Chowdhury S, Chouljenko DV, Kousoulas KG. The Amino Terminus of Herpes Simplex Virus Type 1 Glycoprotein K (Gk) Modulates gB-Mediated Virus-Induced Cell Fusion and Virion Egress. J Virol (2009) 83(23):12301-13. doi: 10.1128/JVI.01329-09

31. Jaggi U, Wang S, Tormanen K, Matundan H, Ljubimov AV, Ghiasi H. Role of Herpes Simplex Virus Type 1 (HSV-1) Glycoprotein K (Gk) Pathogenic CD8 (+) T Cells in Exacerbation of Eye Disease. Front Immunol (2018) 9:2895. doi: 10.3389/fimmu.2018.02895

32. Allen SJ, Mott KR, Matsuura Y, Moriishi K, Kousoulas KG, Ghiasi H. Binding of HSV-1 Glycoprotein K (Gk) to Signal Peptide Peptidase (SPP) is Required for Virus Infectivity. PloS One (2014) 9(1):e85360. doi: 10.1371/ journal.pone. 0085360

33. Allen SJ, Mott KR, Ghiasi H. Overexpression of Herpes Simplex Virus Glycoprotein K (Gk) Alters Expression of HSV Receptors in OcularlyInfected Mice. Invest Ophthalmol Vis Sci (2014) 55(4):2442-51. doi: 10.1167/iovs.14-14013

34. Allen SJ, Mott KR, Ljubimov AV, Ghiasi H. Exacerbation of Corneal Scarring in HSV-1 gK-Immunized Mice Correlates With Elevation of CD8+CD25+ T Cells in Corneas of Ocularly Infected Mice. Virology (2010) 399(1):11-22. doi: 10.1016/j.virol.2009.12.011

35. Mott KR, Perng GC, Osorio Y, Kousoulas KG, Ghiasi H. A Recombinant Herpes Simplex Virus Type 1 Expressing Two Additional Copies of $\mathrm{gK}$ is More Pathogenic Than Wild-Type Virus in Two Different Strains of Mice. J Virol (2007) 81(23):12962-72. doi: 10.1128/JVI.01442-07

36. Buela KA, Hendricks RL. Cornea-Infiltrating and Lymph Node Dendritic Cells Contribute to CD4+ T Cell Expansion After Herpes Simplex Virus-1 Ocular Infection. J Immunol (2015) 194(1):379-87. doi: 10.4049/jimmunol. 1402326

37. Cathcart HM, Zheng M, Covar JJ, Liu Y, Podolsky R, Atherton SS. InterferonGamma, Macrophages, and Virus Spread After HSV-1 Injection. Invest Ophthalmol Vis Sci (2011) 52(7):3984-93. doi: 10.1167/iovs.10-6449

38. Frank GM, Buela KA, Maker DM, Harvey SA, Hendricks RL. Early Responding Dendritic Cells Direct the Local NK Response to Control Herpes Simplex Virus 1 Infection Within the Cornea. J Immunol (2012) 188(3):1350-9. doi: 10.4049/jimmunol.1101968

39. Thomas J, Gangappa S, Kanangat S, Rouse BT. On the Essential Involvement of Neutrophils in the Immunopathologic Disease: Herpetic Stromal Keratitis. J Immunol (1997) 158(3):1383-91.

40. Daheshia M, Kanangat S, Rouse BT. Production of Key Molecules by Ocular Neutrophils Early After Herpetic Infection of the Cornea. Exp Eye Res (1998) 67(6):619-24. doi: 10.1006/exer.1998.0565

41. Tumpey TM, Chen SH, Oakes JE, Lausch RN. Neutrophil-Mediated Suppression of Virus Replication After Herpes Simplex Virus Type 1 Infection of the Murine Cornea. J Virol (1996) 70(2):898-904. doi: 10.1128/ jvi.70.2.898-904.1996

42. Molesworth-Kenyon S, Mates A, Yin R, Strieter R, Oakes J, Lausch R. CXCR3, IP-10, and Mig are Required for CD4+ T Cell Recruitment During the DTH Response to HSV-1 Yet Are Independent of the Mechanism for Viral Clearance. Virology (2005) 333(1):1-9. doi: 10.1016/j.virol.2005.01.005

43. Lepisto AJ, Frank GM, Xu M, Stuart PM, Hendricks RL. CD8 T Cells Mediate Transient Herpes Stromal Keratitis in CD4-Deficient Mice. Invest Ophthalmol Vis Sci (2006) 47(8):3400-9. doi: 10.1167/iovs.05-0898

44. Streilein JW, Dana MR, Ksander BR. Immunity Causing Blindness: Five Different Paths to Herpes Stromal Keratitis. Immunol Today (1997) 18 (9):443-9. doi: 10.1016/S0167-5699(97)01114-6

45. Eaton JS, Miller PE, Bentley E, Thomasy SM, Murphy CJ. The SPOTS System: An Ocular Scoring System Optimized for Use in Modern Preclinical Drug Development and Toxicology. J Ocul Pharmacol Ther (2017) 33(10):718-34. doi: 10.1089/jop.2017.0108

46. Suryawanshi A, Mulik S, Sharma S, Reddy PB, Sehrawat S, Rouse BT. Ocular Neovascularization Caused by Herpes Simplex Virus Type 1 Infection Results From Breakdown of Binding Between Vascular Endothelial Growth Factor A and its Soluble Receptor. J Immunol (2011) 186(6):3653-65. doi: 10.4049/ jimmunol.1003239

47. Azher TN, Yin XT, Stuart PM. Understanding the Role of Chemokines and Cytokines in Experimental Models of Herpes Simplex Keratitis. J Immunol Res (2017) 2017:7261980. doi: 10.1155/2017/7261980

48. Jackson DG. Biology of the Lymphatic Marker LYVE-1 and Applications in Research Into Lymphatic Trafficking and Lymphangiogenesis. APMIS (2004) 112(7-8):526-38. doi: 10.1111/j.1600-0463.2004.apm11207-0811.x

49. Wuest TR, Carr DJ. VEGF-A Expression by HSV-1-Infected Cells Drives Corneal Lymphangiogenesis. J Exp Med (2010) 207(1):101-15. doi: 10.1084/ jem.20091385

50. Li H, Zhang J, Kumar A, Zheng M, Atherton SS, Yu FS. Herpes Simplex Virus 1 Infection Induces the Expression of Proinflammatory Cytokines, Interferons and TLR7 in Human Corneal Epithelial Cells. Immunology (2006) 117 (2):167-76. doi: 10.1111/j.1365-2567.2005.02275.x 
51. Khairallah C, Dechanet-Merville J, Capone M. Gammadelta T Cell-Mediated Immunity to Cytomegalovirus Infection. Front Immunol (2017) 8:105. doi: 10.3389/fimmu.2017.00105

52. Shao L, Huang D, Wei H, Wang RC, Chen CY, Shen L, et al. Expansion, Reexpansion, and Recall-Like Expansion of Vgamma2Vdelta2 $\mathrm{T}$ Cells in Smallpox Vaccination and Monkeypox Virus Infection. J Virol (2009) 83 (22):11959-65. doi: 10.1128/JVI.00689-09

53. Abate G, Eslick J, Newman FK, Frey SE, Belshe RB, Monath TP, et al. FlowCytometric Detection of Vaccinia-Induced Memory Effector CD4(+), CD8 $(+)$, and Gamma Delta TCR $(+)$ T Cells Capable of Antigen-Specific Expansion and Effector Functions. J Infect Dis (2005) 192(8):1362-71. doi: 10.1086/ 444423

54. Shen H, Wang Y, Chen CY, Frencher J, Huang D, Yang E, et al. Th17-Related Cytokines Contribute to Recall-Like Expansion/Effector Function of HMBPPSpecific Vgamma2Vdelta2 T Cells After Mycobacterium Tuberculosis Infection or Vaccination. Eur J Immunol (2015) 45(2):442-51. doi: 10.1002/ eji.201444635

55. Frencher JT, Shen H, Yan L, Wilson JO, Freitag NE, Rizzo AN, et al. HMBPPDeficient Listeria Mutant Immunization Alters Pulmonary/Systemic Responses, Effector Functions, and Memory Polarization of Vgamma2Vdelta2 T Cells. J Leukoc Biol (2014) 96(6):957-67. doi: 10.1189/ jlb.6HI1213-632R

56. Shen Y, Zhou D, Qiu L, Lai X, Simon M, Shen L, et al. Adaptive Immune Response of Vgamma2Vdelta2+ T Cells During Mycobacterial Infections. Science (2002) 295(5563):2255-8. doi: 10.1126/science.1068819

57. Marchitto MC, Dillen CA, Liu H, Miller RJ, Archer NK, Ortines RV, et al. Clonal Vgamma6(+)Vdelta4(+) T Cells Promote IL-17-Mediated Immunity Against Staphylococcus Aureus Skin Infection. Proc Natl Acad Sci USA (2019) 116(22):10917-26. doi: 10.1073/pnas.1818256116

58. Anipindi VC, Bagri P, Dizzell SE, Jimenez-Saiz R, Jordana M, Snider DP, et al. IL-17 Production by Gammadelta(+) T Cells Is Critical for Inducing Th17 Responses in the Female Genital Tract and Regulated by Estradiol and Microbiota. Immunohorizons (2019) 3(7):317-30. doi: 10.4049/ immunohorizons. 1900040

59. Krishnan S, Prise IE, Wemyss K, Schenck LP, Bridgeman HM, McClure FA, et al. Amphiregulin-Producing Gammadelta T Cells are Vital for Safeguarding Oral Barrier Immune Homeostasis. Proc Natl Acad Sci USA (2018) 115 (42):10738-43. doi: 10.1073/pnas.1802320115

60. St Leger AJ, Desai JV, Drummond RA, Kugadas A, Almaghrabi F, Silver P, et al. An Ocular Commensal Protects Against Corneal Infection by Driving an Interleukin-17 Response From Mucosal Gammadelta T Cells. Immunity (2017) 47(1):148-58.e5. doi: 10.1016/j.immuni.2017.06.014

61. Baer A, Colon-Moran W, Bhattarai N. Characterization of the Effects of Immunomodulatory Drug Fingolimod (FTY720) on Human T Cell Receptor Signaling Pathways. Sci Rep (2018) 8(1):10910. doi: 10.1038/s41598-01829355-0

62. Yun H, Rowe AM, Lathrop KL, Harvey SA, Hendricks RL. Reversible Nerve Damage and Corneal Pathology in Murine Herpes Simplex Stromal Keratitis. J Virol (2014) 88(14):7870-80. doi: 10.1128/JVI.01146-14

63. Born WK, Kemal Aydintug M, O’Brien RL. Diversity of Gammadelta T-Cell Antigens. Cell Mol Immunol (2013) 10(1):13-20. doi: 10.1038/cmi.2012.45

64. Bonneville M, O’Brien RL, Born WK. Gammadelta T Cell Effector Functions: A Blend of Innate Programming and Acquired Plasticity. Nat Rev Immunol (2010) 10(7):467-78. doi: 10.1038/nri2781

65. Tagawa T, Nishimura H, Yajima T, Hara H, Kishihara K, Matsuzaki G, et al. Vdelta1+ Gammadelta T Cells Producing CC Chemokines may Bridge a Gap Between Neutrophils and Macrophages in Innate Immunity During Escherichia Coli Infection in Mice. J Immunol (2004) 173(8):5156-64. doi: 10.4049/jimmunol.173.8.5156

66. Sutton CE, Lalor SJ, Sweeney CM, Brereton CF, Lavelle EC, Mills KH. Interleukin-1 and IL-23 Induce Innate IL-17 Production From Gammadelta T Cells, Amplifying Th17 Responses and Autoimmunity. Immunity (2009) 31 (2):331-41. doi: 10.1016/j.immuni.2009.08.001

67. Corpuz TM, Stolp J, Kim HO, Pinget GV, Gray DH, Cho JH, et al. Differential Responsiveness of Innate-Like IL-17- and IFN-Gamma-Producing Gammadelta T Cells to Homeostatic Cytokines. J Immunol (2016) 196 (2):645-54. doi: 10.4049/jimmunol.1502082
68. Born WK, O’Brien RL. Antigen-Restricted Gammadelta T-Cell Receptors? Arch Immunol Ther Exp (Warsz) (2009) 57(2):129-35. doi: 10.1007/s00005009-0017-x

69. Chien YH, Meyer C, Bonneville M. Gammadelta T Cells: First Line of Defense and Beyond. Annu Rev Immunol (2014) 32:121-55. doi: 10.1146/annurevimmunol-032713-120216

70. Hayday AC. Gammadelta T Cells and the Lymphoid Stress-Surveillance Response. Immunity (2009) 31(2):184-96. doi: 10.1016/j.immuni.2009.08.006

71. Itohara S, Farr AG, Lafaille JJ, Bonneville M, Takagaki Y, Haas W, et al. Homing of a Gamma Delta Thymocyte Subset With Homogeneous T-Cell Receptors to Mucosal Epithelia. Nature (1990) 343(6260):754-7. doi: 10.1038/ $343754 \mathrm{a} 0$

72. Gray EE, Suzuki K, Cyster JG. Cutting Edge: Identification of a Motile IL-17Producing Gammadelta T Cell Population in the Dermis. J Immunol (2011) 186(11):6091-5. doi: 10.4049/jimmunol.1100427

73. Havran WL, Allison JP. Origin of Thy-1+ Dendritic Epidermal Cells of Adult Mice From Fetal Thymic Precursors. Nature (1990) 344(6261):68-70. doi: $10.1038 / 344068 \mathrm{a} 0$

74. Goodman T, Lefrancois L. Intraepithelial Lymphocytes. Anatomical Site, Not T Cell Receptor Form, Dictates Phenotype and Function. J Exp Med (1989) 170(5):1569-81. doi: 10.1084/jem.170.5.1569

75. Aljurf M, Ezzat A, Musa OM. Emerging Role of Gammadelta T-Cells in Health and Disease. Blood Rev (2002) 16(4):203-6. doi: 10.1016/S0268-960X (02)00029-2

76. Ribot JC, Neres R, Zuzarte-Luis V, Gomes AQ, Mancio-Silva L, Mensurado S, et al. Gammadelta-T Cells Promote IFN-Gamma-Dependent Plasmodium Pathogenesis Upon Liver-Stage Infection. Proc Natl Acad Sci USA (2019) 116 (20):9979-88. doi: 10.1073/pnas.1814440116

77. Kadivar M, Petersson J, Svensson L, Marsal J. CD8alphabeta+ Gammadelta T Cells: A Novel T Cell Subset With a Potential Role in Inflammatory Bowel Disease. J Immunol (2016) 197(12):4584-92. doi: 10.4049/jimmunol.1601146

78. Sciammas R, Kodukula P, Tang Q, Hendricks RL, Bluestone JA. T Cell Receptor-Gamma/Delta Cells Protect Mice From Herpes Simplex Virus Type 1-Induced Lethal Encephalitis. J Exp Med (1997) 185(11):1969-75. doi: 10.1084/jem.185.11.1969

79. Fitzpatrick S, Lausch R, Barrington RA. CCR6-Positive Gammadelta T Cells Provide Protection Against Intracorneal HSV-1 Infection. Invest Ophthalmol Vis Sci (2019) 60(12):3952-62. doi: 10.1167/iovs.19-27810

80. Huang Y, Yang Z, Huang C, McGowan J, Casper T, Sun D, et al. Gammadelta $\mathrm{T}$ Cell-Dependent Regulatory $\mathrm{T}$ Cells Prevent the Development of Autoimmune Keratitis. J Immunol (2015) 195(12):5572-81. doi: 10.4049/ jimmunol.1501604

81. Sheridan BS, Romagnoli PA, Pham QM, Fu HH, Alonzo F3rd, Schubert WD, et al. Gammadelta T Cells Exhibit Multifunctional and Protective Memory in Intestinal Tissues. Immunity (2013) 39(1):184-95. doi: 10.1016/j.immuni. 2013.06.015

82. Sumaria N, Roediger B, Ng LG, Qin J, Pinto R, Cavanagh LL, et al. Cutaneous Immunosurveillance by Self-Renewing Dermal Gammadelta T Cells. J Exp Med (2011) 208(3):505-18. doi: 10.1084/jem.20101824

83. Ito $\mathrm{Y}$, Usui $\mathrm{T}$, Kobayashi $\mathrm{S}$, Iguchi-Hashimoto $\mathrm{M}$, Ito $\mathrm{H}$, Yoshitomi $\mathrm{H}$, et al. Gamma/delta T Cells are the Predominant Source of Interleukin-17 in Affected Joints in Collagen-Induced Arthritis, But Not in Rheumatoid Arthritis. Arthritis Rheum (2009) 60(8):2294-303. doi: 10.1002/art.24687

84. Zhao Z, Liang Y, Liu Y, Xu P, Flamme-Wiese MJ, Sun D, et al. Choroidal Gammadelta $\mathrm{T}$ Cells in Protection Against Retinal Pigment Epithelium and Retinal Injury. FASEB J (2017) 31(11):4903-16. doi: 10.1096/fj.201700533R

85. Li Z, Burns AR, Miller SB, Smith CW. CCL20, Gammadelta T Cells, and IL-22 in Corneal Epithelial Healing. FASEB J (2011) 25(8):2659-68. doi: 10.1096/ fj.11-184804

86. O'Brien RL, Taylor MA, Hartley J, Nuhsbaum T, Dugan S, Lahmers K, et al. Protective Role of Gammadelta T Cells in Spontaneous Ocular Inflammation. Invest Ophthalmol Vis Sci (2009) 50(7):3266-74. doi: 10.1167/iovs.08-2982

87. Li Z, Burns AR, Rumbaut RE, Smith CW. Gamma Delta T Cells are Necessary for Platelet and Neutrophil Accumulation in Limbal Vessels and Efficient Epithelial Repair After Corneal Abrasion. Am J Pathol (2007) 171(3):838-45. doi: 10.2353/ajpath.2007.070008 
88. Skelsey ME, Mellon J, Niederkorn JY. Gamma Delta T Cells are Needed for Ocular Immune Privilege and Corneal Graft Survival. J Immunol (2001) 166 (7):4327-33. doi: 10.4049/jimmunol.166.7.4327

89. Hao J, Dong S, Xia S, He W, Jia H, Zhang S, et al. Regulatory Role of Vgammal Gammadelta T Cells in Tumor Immunity Through IL-4 Production. J Immunol (2011) 187(10):4979-86. doi: 10.4049/jimmunol.1101389

90. Gerber DJ, Azuara V, Levraud JP, Huang SY, Lembezat MP, Pereira P. IL-4Producing $\gamma \delta$ T Cells That Express a Very Restricted TCR Repertoire Are Preferentially Localized in Liver and Spleen. J Immunol (1999) 163(6):3076-82.

91. Bosurgi L, Cao YG, Cabeza-Cabrerizo M, Tucci A, Hughes LD, Kong Y, et al. Macrophage Function in Tissue Repair and Remodeling Requires IL-4 or IL13 With Apoptotic Cells. Science (2017) 356(6342):1072-6. doi: 10.1126/ science.aai8132

92. Ngo VL, Abo H, Maxim E, Harusato A, Geem D, Medina-Contreras O, et al. A Cytokine Network Involving IL-36gamma, IL-23, and IL-22 Promotes Antimicrobial Defense and Recovery From Intestinal Barrier Damage. Proc Natl Acad Sci U.S.A. (2018) 115(22):E5076-E85. doi: 10.1073/pnas.1718902115

93. Sonnenberg GF, Fouser LA, Artis D. Border Patrol: Regulation of Immunity, Inflammation and Tissue Homeostasis at Barrier Surfaces by IL-22. Nat Immunol (2011) 12(5):383-90. doi: 10.1038/ni.2025

94. Liversidge J, Dick A, Cheng YF, Scott GB, Forrester JV. Retinal Antigen Specific Lymphocytes, TCR-Gamma Delta T Cells and CD5+ B Cells Cultured From the Vitreous in Acute Sympathetic Ophthalmitis. Autoimmunity (1993) 15(4):257-66. doi: 10.3109/08916939309115747
95. Srivastava R, Coulon PG, Roy S, Chilukuri S, Garg S, BenMohamed L. Phenotypic and Functional Signatures of Herpes Simplex Virus-Specific Effector Memory CD73(+)CD45RA(high)CCR7(low)CD8(+) TEMRA and CD73(+)CD45RA(low)CCR7(low)CD8(+) TEM Cells Are Associated With Asymptomatic Ocular Herpes. J Immunol (2018) 201(8):2315-30. doi: 10.4049/jimmunol.1800725

Conflict of Interest: Louisiana State University has licensed the VC2 vaccine for genital herpes to Rational Vaccines. KGK serves as a consultant for Rational Vaccines, Inc.

Publisher's Note: All claims expressed in this article are solely those of the authors and do not necessarily represent those of their affiliated organizations, or those of the publisher, the editors and the reviewers. Any product that may be evaluated in this article, or claim that may be made by its manufacturer, is not guaranteed or endorsed by the publisher.

Copyright $\odot 2021$ Nabi, Lewin, Collantes, Chouljenko and Kousoulas. This is an open-access article distributed under the terms of the Creative Commons Attribution License (CC BY). The use, distribution or reproduction in other forums is permitted, provided the original author(s) and the copyright owner(s) are credited and that the original publication in this journal is cited, in accordance with accepted academic practice. No use, distribution or reproduction is permitted which does not comply with these terms. 